\title{
Recrutamento alveolar associado à posição prona em pacientes com SDRA por Influenza H1N1
}

\author{
Alveolar recruitment associated to prone position in H1N1 Influenza SDRA patients \\ Ecrutación alveolar asociada con la posición prona en pacientes con SDRA por Influenza \\ $\mathrm{H} 1 \mathrm{~N} 1$
}

Naíle Rocha Pinheiro", Leila Graziele de Almeida Brito ${ }^{1 *}$.

\begin{abstract}
RESUMO
Objetivo: Avaliar o desfecho pós recrutamento alveolar associado à posição prona em dois pacientes com diagnóstico sugestivo de SDRA por Influenza, originado de H1N1. Detalhamentos de caso: Trata-se de um estudo com dois pacientes, do sexo masculino e feminino, com idade de 39 anos e 52 anos respectivamente, com diagnóstico de SDRA por Influenza originado de H1N1, tendo sido internados num mesmo hospital público do interior da Bahia, no inverno de 2019. Os casos apresentaram evolução inicial dos sintomas semelhante. Foi utilizado como protocolo fisioterapêutico o recrutamento alveolar associado à posição prona, onde foi possível observar alteração nos marcadores de oxigenação e ventilação pulmonar, com melhora em ausculta pulmonar, oximetria periférica, índice $\mathrm{PaO} 2 / \mathrm{FiO} 2$ e complacência pulmonar. Considerações finais: Os pacientes do estudo obtiveram resultados positivos com o uso da manobra de recrutamento alveolar associado à posição prona, porém o caso 2 obteve desfecho final negativo, provavelmente devido à diversas morbidades prévias.
\end{abstract}

Palavras-chave: Influenza aviária, Serviço hospitalar de fisioterapia, Síndrome do desconforto respiratório do adulto.

\section{ABSTRACT}

Objective: To evaluate the outcome after alveolar recruitment associated with the prone position in two patients with a diagnosis suggestive of ARDS due to Influenza, originating from H1N1. Case details: This is a study with two young patients, male and female, aged 39 years and 52 years respectively, diagnosed with ARDS due to H1N1 Influenza, having been admitted to the same public hospital in the interior from Bahia, in the winter of 2019. The cases presented similar initial evolution of symptoms. The alveolar recruitment associated with the prone position was used as a physiotherapeutic protocol, and it was possible to observe changes in the oxygenation and pulmonary ventilation markers, with improvement in pulmonary auscultation, peripheral oximetry, $\mathrm{PaO} 2$ / FiO2 index and pulmonary compliance. Final considerations: The patients in the study obtained positive results with the use of the alveolar recruitment maneuver associated with the prone position, but case 2 had a negative final outcome, probably due to several previous morbidities.

Keywords: Influenza in birds, Hospital physical therapy department, Adult respiratory distress syndrome.

\section{RESUMEN}

Objetivo: Evaluar el resultado tras el reclutamiento alveolar asociado a la posición prona en dos pacientes con diagnóstico sugestivo de SDRA por Influenza, originado por H1N1. Detalles del caso: Se trata de un estudio con dos pacientes jóvenes, hombres y mujeres, de 39 y 52 años respectivamente, diagnosticados de SDRA por Influenza H1N1, ingresados en el mismo hospital público del interior. de Bahía, en el invierno de 2019. Los casos presentaron similar evolución inicial de síntomas. Se utilizó como protocolo fisioterapéutico el reclutamiento alveolar asociado a la posición prona, pudiendo observar cambios en los marcadores de oxigenación y ventilación pulmonar, con mejoría en la auscultación pulmonar, oximetría periférica, índice $\mathrm{PaO} 2$ / FiO2 y distensibilidad pulmonar. Consideraciones finales: Los pacientes del estudio obtuvieron resultados positivos con el uso de la maniobra de reclutamiento alveolar asociada a la posición prona, pero el caso 2 tuvo un resultado final negativo, probablemente debido a varias morbilidades previas.

Palabras clave: Gripe aviar, Servicio de fisioterapia hospitalaria, Síndrome de dificultad respiratoria del adulto.

1 Universidade Estadual do Sudoeste da Bahia (UESB), Jequié - BA. *E-mail: leila.graziele@uesb.edu.br SUBMETIDO EM: 9/2020 


\section{INTRODUÇÃO}

A infecção pelo vírus Influenza A subtipo H1N1, conhecida como gripe suína, é compreendida como uma enfermidade com característica infectocontagiosa provocada por uma variação do vírus Influenza. Há indícios de que o vírus tenha surgido de um processo de mutação de genes humano, suíno e aviário, os quais encontravam-se, de forma simultânea, em porcos (BROOKES SM, et al., 2009).

Segundo WHO (2009) registrou-se um nível de alerta elevado em escala mundial da epidemia provocada pelo vírus Influenza A/H1N1 em 2009, de linhagem suína, confirmando 94.512 casos de influenza A/H1N1, sendo registrados $429(0,45 \%)$ óbitos. Os países que evidenciaram as maiores taxas de letalidade foram a Argentina com 2,4\%, o México com 1,2\% e os Estados Unidos com $0,5 \%$. O Brasil ficou na décima colocação, com $0,1 \%$ de letalidade.

Ainda não são conhecidas as condições favoráveis para a maior ocorrência da doença. No entanto, alguns dados mostram que essas condições variam de acordo com a região. Enquanto em alguns países a maior predominância é em sujeitos de meia idade, no México foi mais predominante em adultos jovens saudáveis (LOPEZ CH, et al., 2009).

Segundo o Ministério da Saúde (MS), a Influenza A H1N1 configurou-se por ser uma pandemia de casos leves com baixa taxa de letalidade. Em 2010, a OMS distribuiu os países em "sem ocorrência de casos", "em transição" e "com transmissão sustentada". O Brasil é considerado atualmente com transmissão sustentada (BRASIL, 2010).

Na Bahia, no ano de 2019, de acordo com o Boletim Epidemiológico da Secretaria de Saúde do Estado da Bahia, até o dia 07/08/2019 foram notificados 1.315 casos de Síndrome da Doença Respiratória Aguda (SDRA), sendo que 237 casos foram confirmados para Influenza, sendo 71 casos ocasionados pelo vírus Influenza A H1N1. No período analisado, foram registrados 79 óbitos por SDRA, sendo 28 por Influenza (SESAB, 2019).

As complicações respiratórias são bastante comuns na Influenza, podendo levar à hospitalização e à morte desses pacientes. Podem se apresentar no início da doença como Insuficiência Respiratória Aguda (IRpA) e evoluir rapidamente para SDRA, necessitando de suporte ventilatório (SOARES SCS e JANAHU LTA, 2011).

Lidar com esta doença do novo século de maneira adequada é um desafio. Os estudos realizados sobre a assistência de alta complexidade aos indivíduos com influenza $\mathrm{A} H 1 \mathrm{~N} 1$, além do avanço dos suportes intensivos, podem levar à redução da mortalidade desse tipo de paciente no futuro (SOARES SCS e JANAHU LTA, 2011).

Apesar do manejo ao paciente com SDRA já estar consolidado na literatura, o manejo de paciente com SDRA por H1N1 ainda não tem sido amplamente discutido. Acredita-se que o recrutamento alveolar associado à posição prona realizado nas primeiras horas do início dos sintomas da SDRA por H1N1 traga benefícios para o paciente, apresentando melhora em complacência pulmonar, hipoxemia e troca gasosa.

Assim, o objetivo deste estudo foi analisar o desfecho pós recrutamento alveolar associado à posição prona em dois pacientes com SDRA por Influenza originado de H1N1, internados num hospital público do interior da Bahia.

\section{DETALHAMENTO DE CASO}

Para a elaboração do caso, foi utilizado o prontuário eletrônico dos pacientes, arquivado no sistema de informações de um hospital público do interior da Bahia. A coleta de dados ocorreu de setembro a outubro de 2019. Os pesquisadores deste estudo buscaram anuência da direção do hospital para que a coleta de dados fosse realizada.

Este projeto foi submetido e aprovado pelo Comitê de Ética em Pesquisa da Universidade Estadual do Sudoeste da Bahia (UESB), sob parecer número 3.668.801 e obedeceu às normas éticas exigidas pela Resolução no 466/2012 do Conselho Nacional de Saúde (CNS). 


\section{Caso 1}

Paciente do sexo masculino, 39 anos, solteiro, procedente de Ipiaú - Bahia. Foi admitido no hospital de Ipiaú no dia 06/06/2019, após história de mal estar, dispneia e dor em região torácica à direita, com início dos sintomas há 8 dias, evoluindo com IRpA, necessitando de intubação orotraqueal, sendo encaminhado para um hospital público no interior da Bahia e posteriormente, admitido na UTI no dia 07/06/2019, permanecendo por 36 dias hospitalizado.

Teve diagnóstico clínico de Influenza por H1N1 e SDRA. A pesquisa para vírus Influenza A (H1N1) foi obtida através do Swab nasofaringe por técnica de PCR real time. Devido ao grande comprometimento pulmonar e difícil manuseio da ventilação mecânica, fez-se necessário o uso de bloqueador neuromuscular.

O hemograma da admissão não apresentou alterações importantes, apenas o LDH apresentou-se elevado $(340,00 \mathrm{U} / \mathrm{L})$. O exame de hemogasometria arterial evidenciou comprometimento importante em trocas gasosas, com baixa relação $\mathrm{PaO}_{2} / \mathrm{FiO}_{2}$, baixa saturação arterial e baixa $\mathrm{PaO}_{2}$.

Ao exame físico as pupilas estavam isocóricas e fotorreagentes, tórax simétrico com expansibilidade satisfatória, murmúrio vesicular diminuído em bases e creptos em hemitórax direito. Extremidades quentes e bem perfundidas e tempo de enchimento capilar menor do que 3 segundos. Quanto aos sinais vitais, a pressão arterial (PA) estava em $93 \times 56 \mathrm{mmHg}$, a frequência cardíaca $(\mathrm{FC})$ era de 71 bpm, em ventilação mecânica invasiva (VMI) por ventilação controlada à pressão (PCV).

A angiotomografia de tórax realizada no dia 07/06/19 foi negativa para tromboembolismo pulmonar, sendo evidenciadas opacidades com atenuação em vidro fosco e extensas áreas de consolidação no parênquima pulmonar acometendo os lobos inferiores dos pulmões (Figura 1).

Figura 1 - Angiotomografia de Tórax realizada no dia seguinte à admissão do paciente.

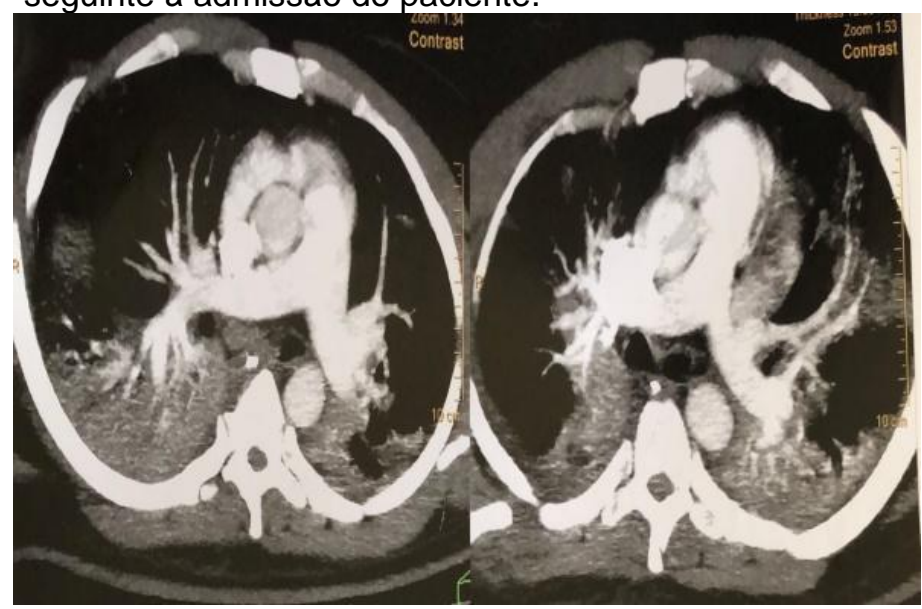

Fonte: PINHEIRO NR e BRITO LGA, 2020.

No dia da admissão na UTI, a equipe de Fisioterapia iniciou protocolo para o recrutamento alveolar associado a posição prona, como estratégia para melhoria da relação $\mathrm{PaO}_{2} / \mathrm{FiO}_{2}$. O paciente permaneceu por 24h pronado. Foi iniciado o recrutamento alveolar com PEEP máxima de $30 \mathrm{cmH}_{2} \mathrm{O}$, sendo feito titulação da PEEP ideal e mantido a ventilação mecânica em PEEP de $22 \mathrm{cmH}_{2} \mathrm{O}$. O protocolo indicava manobra de expansão pulmonar diária, com manutenção de PEEP de $30 \mathrm{cmH}_{2} \mathrm{O}$ por três ciclos de dois minutos.

Após a execução inicial da conduta, houve melhora em marcadores de oxigenação como a $\mathrm{PaO}_{2}$ (de 60 para 70), as trocas gasosas (de 60 para 116), a complacência estática (de 47 para $53 \mathrm{ml} / \mathrm{cmH} 2 \mathrm{O}$ ) e a saturação (de 73 para 94\%).

O paciente ficou adaptado à prótese ventilatória por um período de 27 dias, tendo sido necessários parâmetros altos para manter uma ventilação alveolar adequada (PEEP entre 15 a $20 \mathrm{cmH} 2 \mathrm{O}$, Pressão Controlada de 12 a $14 \mathrm{cmH} 2 \mathrm{O}$, fração inspirada de $\mathrm{O}_{2}$ entre 40 - 60\%). 
A manobra de recrutamento alveolar foi utilizada por vários dias, havendo resposta positiva em $\mathrm{PaO}_{2}(70$ para 100), trocas gasosas (116 para 343), complacência estática (53 para $71 \mathrm{ml} / \mathrm{cmH}_{2} \mathrm{O}$ ) e saturação de $\mathrm{O}_{2}$ (de 94 a 97\%). A tomografia de tórax do dia 22/06/2019 evidenciou regressão significativa das alterações (Figura 2).

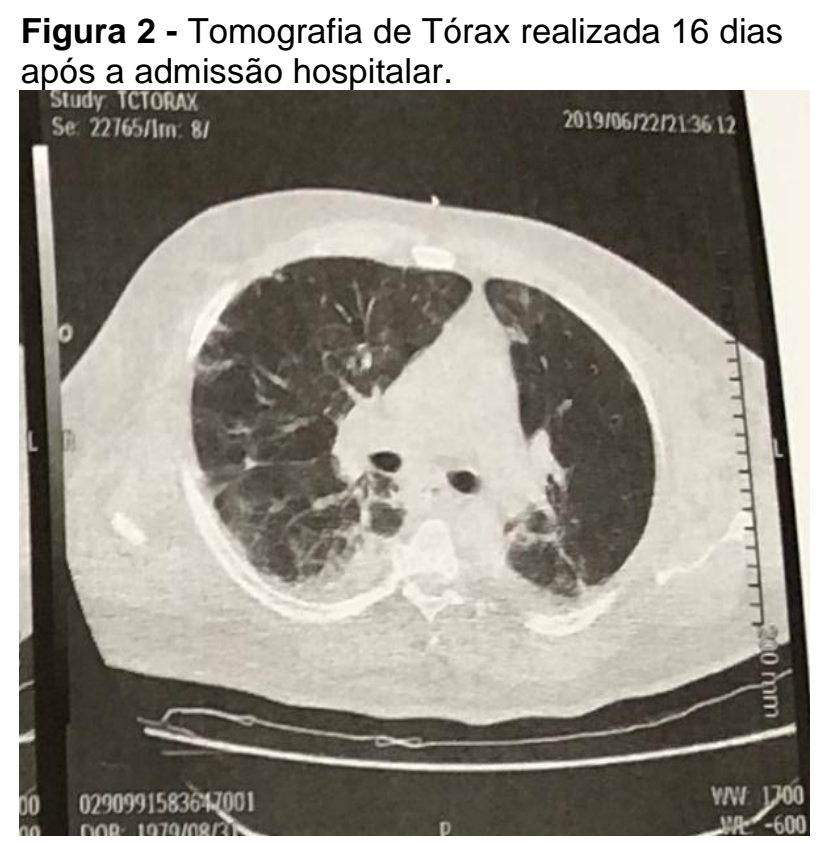

Fonte: PINHEIRO NR e BRITO LGA, 2020.

No dia 22/06/2019 o paciente foi submetido à traqueostomia, tendo sido iniciado o desmame ventilatório e no dia 03/07/2019 foi desconectado da ventilação mecânica. No dia 07/07/2019 foi realizada a decanulação e alta da UTI. Permaneceu na enfermaria por 5 dias, recebendo alta hospitalar no dia 12/07/2019.

\section{Caso 2}

Paciente do sexo feminino, 52 anos, obesa, hipertensa, procedente de Maracás - Bahia. Foi admitida num hospital público do interior da Bahia no dia 22/07/2019 com história de febre associada leucopenia, prostração, instabilidade hemodinâmica, hemoptise e hipoxemia. Admitida na Emergência em uso de máscara de reservatório, mantinha dispneia intensa e baixa oximetria periférica $\left(\mathrm{SpO}_{2} 80 \%\right)$. Foi submetida à intubação orotraqueal hemodinamicamente instável, em uso de noradrenalina $(30 \mathrm{ml} / \mathrm{h})$ e dobutamina $(5 \mathrm{ml} / \mathrm{h})$, sedada com fentanil $(10 \mathrm{ml} / \mathrm{h})$ e dormonid $(10 \mathrm{ml} / \mathrm{h})$. No dia seguinte foi encaminhada para a UTI.

Teve diagnóstico clínico de Influenza por H1N1, Síndrome Respiratória Aguda Grave e Lesão Renal Aguda pré-renal/isquêmica associada a choque séptico de foco respiratório, havendo necessidade de hemodiálise. A pesquisa para vírus influenza $A(H 1 N 1)$ foi obtida através do Swab orofaringe por técnica de PCR real time. Devido ao grande comprometimento pulmonar e difícil manuseio da ventilação mecânica, fez-se necessário o uso de bloqueador neuromuscular.

O hemograma da admissão apresentou leucocitose, trombocitopenia, linfocitose e uremia. O exame de hemogasometria arterial evidenciava acidose respiratória e comprometimento em trocas gasosas, com baixa relação $\mathrm{PaO}_{2} / \mathrm{FiO}_{2}$; baixa saturação e baixa $\mathrm{PaO}_{2}$.

Ao exame físico foram observadas pupilas isocóricas e fotorreagentes, sem abertura ocular espontânea, afebril, em uso de VMI por PCV. O tórax apresentava-se simétrico, extremidades aquecidas e oxigenadas, tempo de enchimento capilar maior do que 4,5 segundos.

Quanto aos sinais vitais, FC de 124 bpm, frequência respiratória (FR) de $32 \mathrm{rpm}$, PA de $133 \times 71 \mathrm{mmHg}$, saturação de $\mathrm{O}_{2}$ de $93 \%$. O raio-x da admissão evidenciou infiltrados alveolares nos quatro quadrantes pulmonares (Figura 3). 
Figura 3 - Raio X da admissão hospitalar.

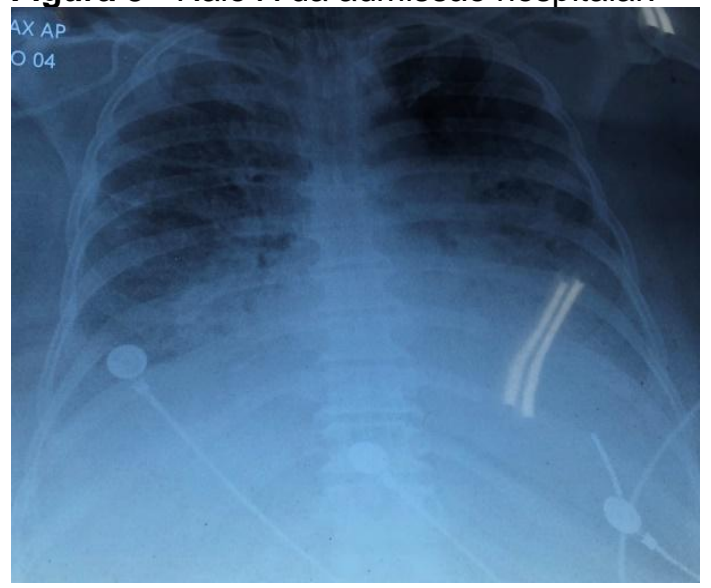

Fonte: PINHEIRO NR e BRITO LGA, 2020.

Diante do quadro, foi iniciado no dia 23/07/2019, pela equipe de Fisioterapia, um protocolo de recrutamento alveolar associado a posição prona como estratégia para melhoria da relação $\mathrm{PaO}_{2} / \mathrm{FiO}_{2}$. A paciente permaneceu por 16 horas pronada e manteve a acidose respiratória em gasometrias seriadas, com ajuste ventilatório progressivo.

Foi iniciado o recrutamento alveolar com PEEP máxima em $35 \mathrm{cmH}_{2} \mathrm{O}$, tendo sido feita titulação da PEEP ideal e mantida a PEEP em $17 \mathrm{cmH}_{2} \mathrm{O}$. O protocolo indicava manobra de expansão com elevação da PEEP até $35 \mathrm{cmH}_{2} \mathrm{O}, 3$ ciclos por 2 min, alternando com PEEP de $30 \mathrm{cmH}_{2} \mathrm{O}$ por 1 minuto.

Após condutas do dia 23/07/2019, houve melhora em marcadores de oxigenação, $\mathrm{PaO}_{2}$ (de 35 para 77), relação $\mathrm{PaO}_{2} / \mathrm{FiO}_{2}$ (de 35 para 77), complacência estática (de 15 para $23 \mathrm{ml} / \mathrm{cmH} 2 \mathrm{O}$ ) e $\mathrm{SpO}_{2}$ (de 58 para 93\%); entretanto, a paciente manteve acidose respiratória $\left(\mathrm{PaCO}_{2}\right.$ maior do que 115).

A manobra de recrutamento foi utilizada até o dia 27/07/2019, havendo resposta positiva em $\mathrm{PaO}_{2}$ (de 77 para 126), trocas gasosas (de 77 para 126), complacência estática (de 23 para $27 \mathrm{ml} / \mathrm{cmH}_{2} \mathrm{O}$ ), $\mathrm{SaO}_{2}$ (de 93 para $95 \%$ ) e $\mathrm{PaCO}_{2}$ (de mais de 115 para 61 ).

Durante o período de internação a paciente cursou com instabilidade hemodinâmica, sendo refratária à altas doses de drogas vasoativas. Apresentou exames laboratoriais sugestivos de tromboembolismo pulmonar (TEP), por isso foi iniciado anticoagulação plena. Também foi constatado pneumotórax através do raio $X$ de tórax (Figura 4 ).

Figura 4 - Pneumotórax em raio x.

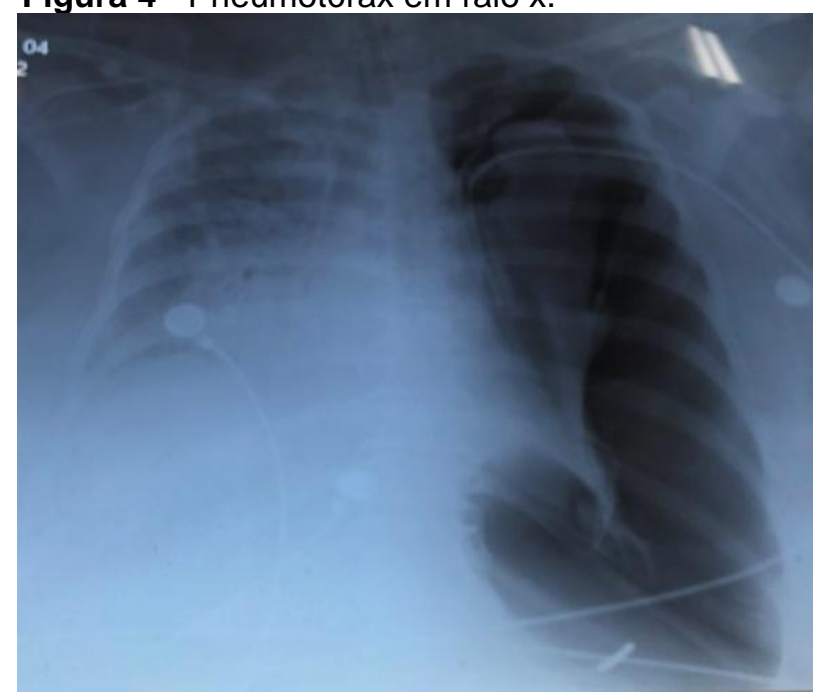

Fonte: PINHEIRO NR e BRITO LGA, 2020. 
Em virtude da piora progressiva na ventilação, foi optado por drenagem de tórax de urgência. A toracostomia à esquerda foi realizada no dia 01/08/2019 e o dreno encontrava-se oscilante, com secreção sanguinolenta e volumosa. A paciente evoluiu com piora clínica, sendo usado drogas vasoativas em alta vazão, porém não obteve resposta ao tratamento medicamentoso, evoluindo para óbito no dia 11/08/2019.

\section{DISCUSSÃO}

Este estudo foi realizado com dois pacientes, do sexo masculino e feminino, com idade de 39 e 52 anos, respectivamente, com diagnóstico de SDRA por Influenza originado de H1N1, que foram internados no mesmo hospital, com evolução inicial dos sintomas semelhante, no qual foram utilizados mesmos recursos terapêuticos, porém com desfecho clínico divergente.

Estudos sugerem que os danos respiratórios podem ocorrer logo no início da patologia e de forma rápida progredir para SDRA (PEREZ-PADILLA R, et al., 2009; SOARES SCS e JANAHU LTA, 2011). Nos dois casos, foi possível observar essa progressão rápida da doença

O recrutamento alveolar associado à posição prona foram medidas terapêuticas utilizadas com ambos os pacientes, sendo possível observar melhora nos marcadores de oxigenação e ventilação pulmonar. Houve melhora em ausculta pulmonar, oximetria periférica, índice $\mathrm{PaO}_{2} / \mathrm{FiO}_{2}$ e complacência pulmonar. Amato MBP, et al. (2007) afirmam que o recrutamento alveolar é essencial para melhorar a ventilação pulmonar em casos de SDRA. A utilização de PEEP progressiva e delta de pressão inspiratória de $15 \mathrm{cmH}_{2} 0$ são medidas que garantem a manutenção da função pulmonar.

Um estudo de série de casos evidenciou em 51 pacientes com SDRA que manobras de recrutamento alveolar diminuíram a área pulmonar não aerada nas regiões dependentes, melhorando a relação $\mathrm{PaO}_{2} / \mathrm{FIO}_{2}$ (CASER EB, 2012).

Os resultados do estudo de Pensier J, et al. (2019) sugerem que em pacientes com SDRA, o uso sistemático de recrutamento alveolar não melhora a mortalidade hospitalar ou tempo de permanência na UTI. O uso de recrutamento alveolar foi associado a efeitos positivos como melhora da oxigenação, diminuição da driving pressure e uso menos frequente de terapia de resgate. No entanto, foi associado também à efeitos negativos, como comprometimento hemodinâmico. Esses resultados apoiam o uso individualizado e não sistemático do recrutamento alveolar em pacientes com SDRA.

A eficácia da VMI convencional é discutida nos casos de SDRA, já que é complexo manter o quadro clínico estável, mesmo associado à outras estratégias, como posição prona, ventilação de alta frequência ou suplementação de óxido nítrico.

A oxigenação por membrana extracorpórea vem mostrando resultados positivos em SDRA, aumentando a sobrevida em 71\% (HUBMAYR RD e FARMER JC, 2010). No entanto, a utilização dessas novas abordagens não faz parte da realidade de grande parte dos hospitais do país. Acredita-se que a maioria dos pacientes com SDRA se beneficiem da posição prona, apresentando melhora da oxigenação. $O$ estudo PROCEVA multicêntrico, controlado e randomizado, envolvendo 466 pacientes com SDRA cuja PaO2/FiO2 era menor do que $150 \mathrm{mmHg}$, submeteu parte dos pacientes à posição prona por $16 \mathrm{~h}$ e evidenciou redução de mortalidade em 28 dias ( $16 \%$ no grupo pronado e $32,8 \%$ no grupo supinado), além de redução de mortalidade em 90 dias (23,6\% no grupo pronado e 41\% no grupo supinado) (GUÉRIN CMD, et al., 2013).

Na posição prona há uma tendência de maior colapso na região inferior do pulmão, que é a região dos alvéolos anteriores. Entretanto, por ter menos alvéolos situados nessa região por razão do formato cônico do pulmão, há evidência de menor área de colapso quando comparado com a posição supino. Por mais que a força da gravidade atue comprimindo os alvéolos da região dependente na posição prona, em virtude da associação das formas pulmonar e da caixa torácica, esse colapso é de menor magnitude (SCHOLTEN EL, et al., 2017).

A mais recente revisão sistemática com metanálise publicada sobre a posição prona em SDRA, em indivíduos com hipoxemia moderada a severa, evidenciou que a mortalidade se reduz em pacientes colocados 
em posição prona por tempo maior do que 12 horas. Quando a posição prona é feita em tempo menor do que 12 horas, não há mudança de risco relativo comparado ao posicionamento supino (MUNSHI L, et al., 2017).

Ambos os pacientes do estudo obtiveram resultados positivos com o uso da manobra de recrutamento alveolar associada à posição prona, porém a paciente do caso 2 obteve 0 desfecho final negativo, provavelmente devido a morbidades prévias, tais como obesidade e hipertensão arterial sistêmica, que são considerados como fatores de risco para complicação. Vale ressaltar que apesar de ambos os pacientes terem sido submetidos à posição prona, o caso 2 permaneceu na posição em menor tempo (16h) em comparação ao caso 1 (24 horas).

$\mathrm{Na}$ literatura não existe consenso sobre a indicação do uso do recrutamento alveolar associado à posição prona e seus possíveis desfechos clínicos, necessitando de mais estudos para identificar qual o grupo de pacientes com SDRA pode se beneficiar desta terapêutica, sendo indicado o uso individualizado e não sistemático da técnica.

\section{REFERÊNCIAS}

1. AMATO MBP, et al. Ventilação mecânica na Lesão Pulmonar Aguda (LPA)/Síndrome do Desconforto Respiratório Agudo (SDRA). J Bras Pneumol. 2007; 33 (2): 119-27.

2. BRASIL. 2010. In: Protocolo de manejo clínico de síndrome respiratória aguda grave -SRAG. Brasília/DF. Disponível em:

http://www.fmt.am.gov.br/layout2011/dam/h1n1/documentos/Protocolo_manejo_clinico_influenza_09_03_10.pdf.

Acesso em: 5 out. 2019.

3. BROOKES SM, et al. Influenza A (H1N1) infection in pigs. Veterinary Record, 2009; 164 (24): 760-761.

4. CASER EB. Estudo da incidência de lesão pulmonar aguda e síndrome do desconforto respiratório agudo nas unidades de terapia intensiva da região da grande Vitória no Espírito Santo. Tese (Doutorado em Ciências). Faculdade de Medicina da Universidade de São Paulo, São Paulo, 2012; 127 p.

5. GUÉRIN CMD, et al. Prone Positioning in Severe Acute Respiratory Distress Syndrome. N. Engl J Med. 2013; 368: 2159-2168.

6. HUBMAYR RD, FARMER JC. Should we "rescue" patients with 2009 influenza A (H1N1) and lung injury from conventional mechanical ventilation? Chest. 2010; 137 (4): 745-747.

7. LOPEZ CH, et al. Neumonía y syndrome de distress respiratório agudo producido por el virus influenza A (H1N1). Med Intensiva. 2009; 33 (9): 455-8.

8. MUNSHI L, et al. Prone Position for Acute Respiratory Distress Syndrome: a Systematic Review and Meta-Analysis. Ann Am Thorac Soc. 2017; 14: 280-288.

9. PENSIER J, et al. Effect of lung recruitment maneuver on oxygenation, physiological parameters and mortality in acute respiratory distress syndrome patients: a systematic review and meta-analysis. Intensive Care Med. 2019; 45: 16911702.

10. PEREZ-PADILLA R, et al. Pneumonia and respiratory failure from swine-origin influenza A (H1N1) in Mexico. New England journal of medicine, 2009; 361 (7): 680-689.

11. SESAB. 2019. In: Boletim Epidemiológico da Influenza. Bahia. Disponível em: http://www.saude.ba.gov.br/wpcontent/uploads/2017/11/2019-Boletim-Epidemiol\%C3\%B3gico-da-Influenza-Bahia-n.-06.pdf. Acesso em: 8 out. 2019.

12. SCHOLTEN EL, et al. Treatment of ARDS With Prone Positioning. Chest, 2017;151(1):215-224.

13. SOARES SCS, JANAHU LTA. O suporte ventilatório no tratamento da Influenza A H1N1 em Unidade de Terapia Intensiva. Rev Pan-Amaz Saude, 2011; 2(1): 79-84.

14. WORLD HEALTH ORGANIZATION. 2009. In: World now at the start of 2009 influenza pandemic. Disponível em: https://www.who.int/mediacentre/news/statements/2009/h1n1_pandemic_phase6_20090611/en/. Acesso em: 1 out. 2019. 